ISSN : 2550-0198

\title{
OPTIMALISASI PERALATAN LABORATORIUM FISIKA BAGI GURU MATA PELAJARAN FISIKA SMA KOTA PEKANBARU
}

\author{
Delovita Ginting*, Sri Fitria Retnawaty, Noni Febriani, Yulia Fitri, Shabri Putra Wirman, \\ Neneng Fitrya \\ Program Studi Fisika, Universitas Muhammadiyah Riau \\ *email: delovita@umri.ac.id
}

\begin{abstract}
Abstrak
Salah satu strategi pembelajaran ilmu fisika yang baik adalah penerapan model pembelajaran berbasis praktikum. Hampir di sebagian SMA sarana dan prasarana masih sangat kurang dan minim salah satunya ruang dan fasilitas alat-alat laboratorium yang menyebabkan pelaksanaan proses pembelajaran fisika belum terlalu dapat dioptimalkan dan hal ini dapat mempengaruhi pemahaman siswa dalam proses pembelajaran fisika. Tujuan dari pengabdian ini adalah memberikan informasi kepada pengelola laboratorium atau guru fisika SMA di Pekanbaru sehingga dapat meningkatkan pemahaman, motivasi, kreatifitas guru dalam merancang, membuat dan menggunakan media pembelajaran yang ada di sekitar dengan memodifikasinya untuk kegiatan praktikum. Kegiatan pengabdian kepada masyarakat (PPM) ini dilaksanakan bertempat di laboratorium Fisika SMAN 1 Pekanbaru selama 3 jam, total peserta yang hadir dalam kegiatan tersebut berjumlah 17 orang guru fisika dari 17 sekolah yang ada di kota Pekanbaru. Peserta memperoleh tambahan informasi, pengetahuan, pengalaman tentang materi atau modul praktikum yang telah diberikan, peserta ingin menerapkan hasil yang diperoleh di sekolah yang diajar.
\end{abstract}

Kata kunci: Optimalisasi, Laboratorium, fisika, siswa SMA, praktikum

\section{PENDAHULUAN}

Mata pelajaran IPA berbeda dengan mata pelajaran lainnya. Salah satu perbedaan mata pelajaran IPA dengan mata pelajaran yang lain yaitu dalam proses pembelajarannya IPA memerlukan ruangan khusus yang biasa disebut sebagai laboratorium untuk melakukan kegiatan praktikum[1]. Keberadaan laboratorium tersebut sebagai salah satu sarana penunjang untuk keberhasilan pendidikan. Sehingga keberadaan laboratorium menjadi sangat penting di dalam sekolah untuk berlangsungnya kegiatan belajar mengajar [2].

Kegiatan praktikum merupakan bagian yang tidak terpisahkan dalam pembelajaran fisika, karena dengan kegiatan ini akan diperoleh pengalaman yang meliputi ranah kognitif, afektif dan psikomotor. Alat-alat laboratorium dapat dimanfaatkan sebagai media atau sarana di dalam proses pembelajaran, di laboratorium, kelas maupun dibawa keluar kelas/lingkungan, dengan keterampilan proses, siswa bukan hanya menjadi lebih terampil tetapi juga mempengaruhi pembentukan sikap ilmiah dan juga pencapaian hasil pengetahuannya [3].

Banyak faktor yang menyebabkan ketidakberhasilan siswa dalam mencapai hasil belajar pada mata pelajaran fisika. Faktor-faktor tersebut antara lain faktor eksternal siswa. Faktor internal meliputi: intelegensi, sikap, bakat, dan motivasi siswa. Sedangkan salah satu faktor eksternalnya adalah peran 
guru [4]. Sebagai pengelola pembelajaran, guru harus mampu mengorganisasi dan menggali potensi-potensi yang ada pada diri siswa agar dapat meningkatkan hasil belajar siswa. Potensi siswa dapat dilihat dari proses praktikum di laboratorium.

Salah satu strategi pembelajaran ilmu fisika yang baik adalah penerapan model pembelajaran berbasis praktikum. Pada pembelajaran berbasis praktikum peserta didik lebih diarahkan pada experimental learning (belajar berdasarkan pengalaman konkrit), diskusi dengan teman yang selanjutnya akan diperoleh ide dan konsep. Pembelajaran berbasis praktikum dapat digunakan sebagai alternatif pembelajaran yang dapat mendorong peserta didik belajar aktif untuk mengkontruksi kembali pemahaman konseptualnya[5].

Hampir di sebagian SMA sarana dan prasarana masih sangat kurang dan minim salah satunya ruang dan fasilitas alat-alat laboratorium IPA yang menyebabkan pelaksanaan proses pembelajaran sains IPA khususnya fisika belum terlalu dapat dioptimalkan dan hal ini dapat mempengaruhi pemahaman siswa dalam proses pembelajaran fisika, begitu pula masih ada guru yang kurang kreatif dalam menggunakan media pembelajaran dengan berbagai alasan, seperti faktor ketersediaan alat dan bahan praktikum, keterbatasan dana, waktu dan lainlain. Oleh karena itu khalayak sasaran diutamakan adalah guru-guru fisika untuk menguatkan pondasi dasar mereka di bidang fisika sehingga diharapkan dapat meningkatkan kreativitasnya dalam proses pembelajaran praktikum kepada siswa di sekolah.

Tujuan dari pengabdian ini adalah memberikan informasi kepada pengelola laboratorium atau guru fisika SMA di Pekanbaru sehingga dapat meningkatkan pemahaman, motivasi, kreatifitas guru dalam merancang, membuat dan menggunakan media pembelajaran yang ada di sekitar dengan memodifikasinya untuk kegiatan praktikum IPA-fisika di sekolahnya masing-masing.

\section{METODE PENGABDIAN}

Kegiatan pengabdian kepada masyarakat (PPM) ini dilaksanakan bertempat di laboratorium Fisika SMAN 1 Pekanbaru selama 3 jam, total peserta yang hadir dalam kegiatan tersebut berjumlah 13 orang guru fisika dari 13 sekolah yang ada di kota Pekanbaru.

Tabel.1 Kegiatan materi dan waktu yang disampaikan selama pelatihan

\begin{tabular}{|c|c|c|}
\hline No & Pukul & $\begin{array}{l}\text { Kegiatan dan Jenis } \\
\text { Materi yang diberikan }\end{array}$ \\
\hline 1 & $08.00-08.15$ & $\begin{array}{cc}\text { Sarapan } & \text { dan } \\
\text { peserta datang } & \end{array}$ \\
\hline 2 & $08.15-08.20$ & $\begin{array}{l}\text { Pembukaan oleh } \\
\text { protokol }\end{array}$ \\
\hline 3 & $08.25-08.30$ & $\begin{array}{l}\text { Pembukaan oleh } \\
\text { ketua pelaksana }\end{array}$ \\
\hline 4 & $08.30-09.30$ & \begin{tabular}{l}
\multicolumn{2}{c}{ Ceramah dan } \\
diskusi penjelasan \\
modul $1,2,3,4$, dan 5 \\
secara paralel (peserta \\
dibagi 5 kelompok)
\end{tabular} \\
\hline 5 & $09.30-10.30$ & Praktikum \\
\hline 6 & $10.30-11.00$ & $\begin{array}{r}\text { Diskusi } \\
\text { tanya jawab }\end{array}$ \\
\hline
\end{tabular}

Pada setiap tahap kegiatan dilakukan evaluasi dengan cara berupa tanya jawab (diskusi) dan 
pengamatan oleh peserta (guru fisika). Evaluasi ini menyangkut pengenalan alat laboratorium, penyerapan materi, demonstrasi (peragaan) dan pengamatan langsung. Tim pelaksana mengusahakan adanya masukanmasukan, tanya jawab dan juga diskusi secara nonformal dengan peserta serta praktek langsung untuk mengatasi masalah yang mungkin muncul dan untuk menunjang keberhasilan tujuan dan manfaat kegiatan.

Modul yang dirancang dalam kegiatan ini adalah: gerak pada bidang miring, pegas, kalorimeter, kisi difraksi, listrik, dan osiloskop.

\section{HASIL DAN PEMBAHASAN}

Peserta pelatihan dapat menerima dengan mudah dari 5 materi pelatihan yang diberikan (Tabel 2.) tentang listrik dan gerak karena penyajian materi dan tanya jawab berlangsung singkat dari rentang waktu yang diberikan, sedangkan beberapa materi yang kurang dipahami penerapannya oleh para peserta pelatihan diantaranya adalah kisi difraksi, kalorimeter dan osiloskop, penyampaian materi lebih lama dan pertanyaan yang muncul lebih banyak.

Materi yang diharapkan dari kegiatan PPM ini ke depannya adalah materi fisika yang mengarah pada otomatisasi. Osiloskop merupakan modul yang sangat diminati untuk kembali disampaikan.

Beberapa sekolah mengharapkan pelaksanaan PPM dapat dilaksanakan langsung di laboratorium sekolah masing-masing dan modul yang dirancang dapat disesuaikan dengan kondisi laboratorium sekolah tersebut. SIMPULAN
Peserta memperoleh tambahan informasi, pengetahuan, pengalaman tentang materi atau modul praktikum yang telah diberikan, peserta ingin menerapkan hasil yang diperoleh di sekolah yang diajar.

Kegiatan serupa sebaiknya dilaksanakan kembali dalam rentang 1 bulan atau hingga 2 bulan, sehingga manfaat praktikum fisika sebagai penunjang kegiatan pemahaman materi matapelajaran fisika dapat optimal.

\section{UCAPAN TERIMAKASIH}

Terimakasih kepada Universitas Muhammadiyah Riau sebagai pihak yang memberikan dana untuk pelaksanaan kegiatan ini. Terimakasih kepada Lembaga Penelitian dan Pengabdian kepada Masyarakat (LP2M) sebagai lembaga media dan administrasi pengurusan kegiatan ini. Terimakasih kepada pihak SMAN 1 Pekanbaru yang telah memfasilitasi tempat kegiatan ini. Terimakasih kepada seluruh anggota MGMP (Musyawarah Guru Mata Kuliah) Fisika se-Pekanbaru yang telah hadir memenuhi undangan kegiatan ini. Terimakasih kepada semua dosen Fisika UMRI dan mahasiswa yang terlibat dalam pelaksana kegiatan ini.

\section{DAFTAR PUSTAKA}

[1] Susilana, Rudi, M. Si, and Cepi Riyana. Media Pembelajaran: Hakikat, Pengembangan, Pemanfaatan, dan Penilaian. CV. Wacana Prima, 2009.

[2] Richardson, J. S. (1957). Science teaching in secondary schools. New Jersey: PrenticeHall, Inc.

[3] Freedman, M. P. Relationship among laboratory instruction, attitude toward sciense, and 
achievement in science knowledge. Journal of Research in Science Teaching (vol: 34). New York: John Willey \& Sons. (1997).

[4] Alberta. Alberta Learning, and Alberta. Learning and Teaching Resources Branch. Focus on inquiry: A teacher's guide to implementing inquiry- based learning. Alberta Learning, 2004.

[5] Gasong, D.. Model Pembelajaran Konstruktivistik sebagai Alternatif Mengatasi Masalah Pembelajaran. Jurnal Petra. 2006. 